that a remarkably small proportion of at, least the travelling public are immune to sea-sickness. Consequently the Navy's researches into its prevention deserve a wider audience than habitual sailors. Trials have been going on for many years, but the difficulty of defining and measuring important variables has often led to questionable or conflicting results. The drug now preferred, according to the report, is L-hyoscine as giving the greatest protection in conjunction with the least side-effects. Though ordinarily taken by mouth, it might have to be self-injected by survivors on rafts in a rough sea if they are to remain in full control of their faculties and avoid dehydration by vomiting, so the best way of carrying out this procedure is at present being investigated.

As well as research into labyrinthine function because of its relation to motion sickness the Navy is carrying out a variety of investigations into the ear's other sensory mode, its auditory function. Many sailors have been deafened by gunfire, and the report notes that there is a great need for an earplug that will protect against high-intensity impulsive noises yet cause minimal interference with speech communication. Research into this problem, if it led to the development of a workable device, would bring benefits far beyond the range of gunfire to men employed on noisy industrial processes. Radiological protection must nowadays also loom large in any Service medical programme, and Alverstoke is providing training courses, carrying out inspections, and sponsoring research. All told, the annual report shows it to be very much aware of the Navy's health needs and active in promoting research into them.

\section{Cautionary Tales}

Those alarming booklets, the annual reports of the two London-based medical defence societies, have recently reached their members. ${ }^{12}$ The Scottish one will no doubt soon be out with similar cautionary tales. The familiar hazards still loom large to trap the unwary doctor-and especially surgeon. A number of cases are noted, for instance, in which a swab or instrument was left in the abdomen, others in which the operation was performed on the wrong part or the wrong side.

Errors in diagnosis figure prominently in these cases, and once again the need for $x$-ray examination of patients who have sustained an injury is stressed. One report makes the

1 The Medical Defence Union, Annual Report, 1968.

2 The Medical Protection Society, Annual Report and Accounts, 1968. point that a hair-line fracture may not show until the film is dry, so that further careful scrutiny of it then is essential. But considerable sympathy must be felt for the surgeon who, at an operation for appendicectomy on a young man, excised what seemed to be an ectopic testicle in the abdomen after noting the apparent absence of one in the scrotum on that side. Though he acted with the best of intentions against the development of malignant change, he was mistaken in his diagnosis, for the tumour was a neurilemmoma and the scrotum did contain both testicles. A part of the femoral nerve had been removed with the tumour, and the patient was left lame, for which damages of $£ 7,400$ were paid.

But if traditional hazards linger on, new ones have arrived to waylay the doctor. An error in a computer programme led to a house officer's receiving a special allowance to which he was not entitled. When it was discovered after five months, the doctor paid back the excess. But the computer continued to pay too much, and this was not discovered till seven months later, when, to make matters worse, the sum overpaid was found not to be correct for the allowance but less. When a demand to repay this was made, the doctor called in his defence organization, and its view prevailed that "when such administrative incompetence is disclosed the administration should suffer and not the innocent person." The hospital wrote off the amount.

Another new source of trouble for the unwary is television. The ethical pitfalls of tele-appearances have been discussed in these columns from time to time, but another aspect now reported deserves some thought. An interview with a doctor was recorded by the B.B.C. under conditions of strict anonymity, on which she had insisted. But when broadcast it was interspersed with interviews with another doctor and two patients, in which her name was repeatedly mentioned, so that it was made to appear that everyone was in the studio at the same time. The G.M.C. took notice of this, but did not pursue the matter when the facts were explained. The B.B.C., when challenged on its conduct, was found by the doctor's defence society to have "done everything possible to ensure that all their producers were aware of the requirement of anonymity and that the fault in this case was the result of human error." So far so good, but what is not generally realized is that apparently "live" programmes are often edited, so that what may appear to be a continuous series of events is composed of separate events joined together. There is nothing underhand about this, and in fact the construction of some types of programme would be impossible without it. But clearly great responsibility does rest on television producers - and is no doubt acknowledged - to present a medical programme without distortion. And doctors who undertake to appear in programmes should bear in mind that only a part of what they say or do may in fact be broadcast. 